\title{
ADVANCED LIGHT WATER REACTOR UTILITY REQUIREMENTS DOCUMENT
}

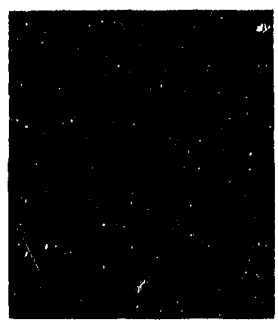

\section{EXECUTIVE SUMMARY}

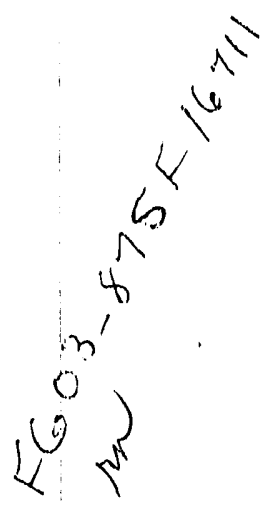

PREPARED BY

ELECTRIC POWER RESEARCH INSTITUTE ADVANCED LWR PROGRAM

PALO ALTO, CALIFORNIA JUNE 1986

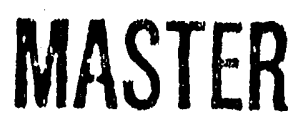


THE ADVANCED LIGHT WATER REACTOR

UTILITY REDUIREMENTS DOCUMENT

\section{PART I: EXECUTIVE SUMMARY}

Prepared by:

The Electric Power Research Institute

Advanced Light Water Reactor Program

Palo Alto, California

June 1986

\section{DISCLAIMER}

This report was prepared as an account of work sponsored by an agency of the United States

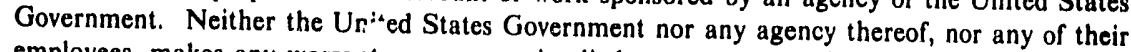
employees, makes any warranty, express or implied, or assumes any legal liability or responsibility for the accuracy, completeness, or usefulness of any information, apparatus, product, or process disclosed, or represents that its use would not infringe privately owned rights. Reference herein to any specific commercial product, process, or service by trade name, trademark, manufacturer, or otherwise does not necessarily constitute or imply its endorsement, recommendation, or favoring by the United States Government or any agency thereof. The views and opinions of authors expressed herein do not necessarily state or reflect those of the United States Government or any agency thereof. 


\section{PREFACE}

EPRI has established an Advanced Light Water Reactor (ALWR) Program to provide leadership in utility industry efforts to assure a viable nuclear power option in the United States.

The ALWR Requirements Document is a primary work product of the EPRI Program. This document is an extensive compilation of the utility requirements for design, construction and performance of advanced light water reactor power plants for the 1990 s and beyond. The Requirements Document's primary emphasis is on resolution of significant problems experienced at existing nuclear power plants. It is intended to be used with companion documents, such as utility procurement specifications, which would cover the remaining detailed technical requirements applicable to new plant projects.

The ALWR Requirements Document consists of several major parts. This volume is Part I, The Executive Summary. It is intended to serve as a concise, management level synopsis of advanced 1 ight water reactors including design objectives and philosophy, overall configuration and features, and the steps necessary to proceed from the conceptual design stage to a completed, functioning power plant.

Part II of the Requirements Document is the set of utility requirements applicable to entire advanced light water reactor plants. It consists of thirteen chapters, beginning with overall plant design requirements (Chapter 1) and proceeding through detailed requirements for each major portion of the plant. Important supporting technical evaluations and other backup material are compiled in Part III of the Requirements Document. 
The ALWR requirements articulated in the Requirements Document are, by conscious choice, extremely challenging ones. In that they are to be applied to a nuclear power plant design which has not yet begun, it is not possible at this point to guarantee that all the requirements can be met. As challenging as these requirements are, however, they are rooted in real world experience and they are considered to be both achievable and central to the goal of producing a viable nuclear plant option in this country.

The Requirements Document is a work of considerable significance to the future of nuclear power in the United States. It represents the technical basis for the next generation of 1 ight water reactors as determined by the utility companies which will build and operate them, based on U.S. and overseas experience over the past quarter of a century, and it provides a technically sound and realistic foundation for the design, construction and operation of safe, reliable and economical plants. 


\section{INTRODUCTION}

\subsection{Background}

EPRI's overal1 goal in its advanced light water reactor work has been to support U.S. utility industry efforts to make available a viable nuclear power generation option for the 1990s and beyond. Toward that end, in 1983 EPRI embarked on a major program of regulatory stabilization, working with the Nuclear Regulatory Commission to identify and resolve key issues related to the licensing of light water reactors. In 1985 two additional major program phases were added: the development of a comprehensive set of requirements applicable to the advanced light water reactor design, and the assessment of small plant options. This threepronged effort is being managed as a single major EPRI program involving extensive U.S. utility input and guidance, and incorporating the efforts of a broad spectrum of industry contractors. The EPRI ALWR Program is planned as a five-year effort with completion in 1989.

Underlying EPRI's and the utility industry's significant commitment of resources towards the ALWR Program are two key assumptions:

- It is assumed that there will be a need for new electric power generation capacity in the years ahead, and that nuclear power will be a necessary choice to meet that need. It is not the purpose of the ALWR Program or the Requirements Document to explore institutional issues such as nuclear plant marketing or the Nation's energy policy. The Program is founded, however, on the premise that there will be a re-vitalized market for nuclear power plants in the United States if plants can be made available which truly meet the needs of the utility users. 
- Secondly, it is assumed that there will be significant and effective licensing reforms in place by the time the ALWR is ready for implementation. The EPRI regulatory stabilization portion of the ALWR Program addresses technical aspects of reactor licensing, but this is only one piece of the problem. It is EPRI's view that there must be a major improvement to the institutional process of licensing new nuclear reactors in the U.S.; otherwise, the risk to investors due to regulatory uncertainty alone could be great enough to discourage public utility investment in new nuclear power plants, regardless of their safety, technical, or economic merit.

\subsection{ALWR Fundamental Objectives}

If the advanced light water reactor is to achieve its overall goal that is, to be a viable candidate for selection by U.S. utilities to meet their capacity addition needs in the next decade - it must meet the following tests:

- Technical Excellence - the ALWR must be an outstanding power generation system in a 11 respects, including safety, technical performance and environmental capability.

- Economic Advantage - the ALWR must be economically attractive in comparison to its competitors on a life cycle cost basis.

- Investment Protection - the ALWR must provide very high protection of the utility investment, particularly in terms of

- extremely low risk of severe accident

- assured Ticensability 
- predictable construction cost and schedule

- predictable operating cost and plant availability

In short, the ALWR Program must define a highly credible nuclear plant design basis on which all involved - including suppliers, investors, regulators and the general public - can proceed with confidence.

\subsection{ALWR Design Philosophy}

Based on extensive input from U.S. nuclear utility companies, the following set of fundamental philosophies has been established to guide the development of the ALWR requirements and conceptual design:

\section{Safety}

Nuclear safety is of paramount importance and must play a dominant role in the development of ALWR requirements. While the safety record of existing U.S. nuclear plants has been very good, ambitious safety targets have been established for the ALWR to achieve an even higher level of safety. All aspects of ALWR development are being pursued with highest emphasis on safety.

Safety considerations in the ALWR Program extend we 11 beyond hardware-oriented "lessons learned" from existing plants. Thorough attention is given to man-machine interface, plant simplification, design margins, and appropriate risk assessments as means of achieving meaningful further improvement in nuclear plant safety. 
There is consensus that the growing complexity in U.S. nuclear plants is adversely impacting those plants in virtually all respects, including safety, initial capital cost, operating cost, avallability, operability, and maintainability. For that reason a very high premium is being placed on simplification as a fundamental means of achieving ALWR Program Requirements.

The Requirements Document presents numerous opportunities for nuclear plant simplification compared to current vintage plants. Among these are the development of systems which are more straightforward (and therefore understandable and predictable) in operation, more reliance on passive safety characteristics, improved accessibility for maintenance and operation, and less complex piping and valve configuration (made possible by reduction of required modes of operation of a given system).

\section{- Design Margin}

As a design philosophy related to simplicity, it is intended that the ALWR be a "robust" plant with substantial built-in margin to provide inherent capability to deal with adverse situations. This objective is reflected in requirements such as those for improved core thermal margin and larger reactor coolant system inventories, compared to current vintage nuclear plant designs. Such features provide direct benefits in terms of reduced demands on man and machine under off-normal conditions. 
The ALWR design is based on proven technology; its success is not dependent upon as yet untested technological advances. This concept is a reflection of the extraordinary data base available from many years of successful operation of light water nuclear power plants in the United States and world-wide. Design concepts, analytical methods, and hardware specifics have been refined to the point that there now is a demonstrated success path in virtually every aspect of plant design. While continuing development of new concepts is important over the long term, departures from proven technology are not considered to be necessary to support ALWR deployment in the 1990s time frame.

To the extent possible, judgements regarding plant experience, and resultant ALWR design choices, will be based on evaluation of statistical data from the Institute of Nuclar Power Operations (INPO), utility owners' groups, the Federal Government, and other recognized souces.

It should be noted that reliance on proven nuclear plant technology does not preclude application of available technological improvements from other sources. Where existing power plant experience warrants consideration of such improvements, this will be done. Incorporation of design features proven in comparable but not identical applications as the ALWR may be appropriate in some cases. These cases wi11 be evaluated based on factors such as potential beneit, available experience base and similarity to ALWR application, consequences of failure, and available alternatives. 
The Requirements Document is written by and for utility companies which own and operate U.S. Nuclear stations. Theirs is the bulk of experience on which to base ALWR design requirements and they must make the selection of future electricity generation systems. Most importantly, plant owner/operators bear ultimate responsibility for the safety and performance of their plants to the public, their customers, and their stockholders. For these reasons EPRI is working very closely with utlility companies in the planning, preparation, and approval of the Requirements Document. A Utility Steering Committee of experienced utility company executives has been established to guide actively the Requirements Document effort and to serve as an interface between EPRI and the utility industry.

\subsection{Elimination of Regulatory Uncertainty}

As noted in 1.2 above, assured licensability is one key element in ALWR acceptance. Toward that end, the U.S. Nuclear Regulatory Commission (NRC) is directly involved in the Requirements Document effort, in the following ways:

- Through the regulatory stabilization effort (a companion program to the Requirements Document preparation, within the EPRI ALWR Program), the utilities are working with NRC to identify and resolve outstanding ALWR licensing issues. This effort is closely linked with the Requirements Document preparation, and the results are incorporated in each Requirements Document chapter. 
- NRC wil1 review the Requirements Document and wil1 prepare a formal Safety Evaluation Report (SER) on each chapter and on the document as a whole.

- Vendor design certification efforts as sponsored by the U.S. Department of Energy (DOE) are being cloiely coordinated with the EPRI ALWR Program to ensure that vendor submittals to NRC are fully consistent with the Requirements Document. 


\section{THE ALWR POWER PLANT}

This section descrtbes the ALWR power plant, as currentiy envisioned, in terms of the utility requirements regarding safety, performance, cost and other attributes. By comparison with today's nuclear plants, these requirements represent substantial improvements in a 11 respects. As challenging as they are, however, the requirements are considered achievable with concerted effort and employing the design philosophy outlined in Section 1. above.

\subsection{Genera 1}

The ALWR plant can be either a PWR or a BWR. Use of either of these proven technologies is consistent with the design philosophy of reliance on experience.

The ALWR plant size can be of any size up to 1350 MWe, again consistent with existing experience. Depending on circumstances, plants at either end of the size spectrum may be attractive to utility investors. For utilities with a need for large capacity additions, a single large (900 - 1350 MWe) unit offers significant potential benefit in terms of economy of scale. For other utility systems, smaller plants may be preferable because of lower capital cost and better matching with capacity requirements.

Fundamentally, the ALWR requirements can apply to units in either size category. However, for consistency the Requirements Document economic evaluations are based on a single size (1100 MWe) unit, and where design features are size dependent they are identified as such.

The ALWR Requirements Document covers an entire plant including interfaces with its environment and with the utility electrical grid. This is based on Utility experience that many existing problems stem from inadequate integration of nuclear and non-nuclear portions of the plant. 


\subsection{Safety}

The ALIVR will be designed and constructed such that it is substantially safer than existing plants. In particular:

0 The plant is to be designed so that for any severe accident which is likely to occur more frequently than once per million years, the dose to someone residing one-half mile from the reactor would be less than $25 \mathrm{rem}$ whole body, a level at which no observable health effects will occur. This covers hoth internai and external initiating events.

0 The plant will be designed to a target mean annual core damage frequency of less than $10^{-5}$ events per year.

- The plant is designed to handle easily many events which before have been considered potential safety concerns. For example, the plant is being designed so that a small break loss of coolant accident, up to an equivalent six-inch diameter, will result not only in no public safety threat, but (on a best estimate basis) will also result in no fuel damage.

- The ALWR will incorporate those features, such as ECCS and containment which are required to ensure that all the design basis safety analysis events can be accommodated. Higher reliability will be achieved by simplifying the ECCS systems, such as by minimizing multiple alignments and functions and eliminating unnecesssary cross-connections.

$\checkmark$ The plant will be designed so that there are fewer challenges to the safety systems over the life of the plant. Improved features will include increased core thermal margin, slower plant response to allow more time for action to be taken before 
safety limits are reached, and where practical, features to eliminate problems which have occurred in existing plants such as potential embrittlement of the reactor pressure vessel.

\subsection{Performance}

\subsubsection{Availability}

The performance of the ALWR plant will be substaritially improved over that of current plants. The ALWR is designed for a lifetime average annual availability of $87 \%$. This inproved availability is to be obtained by a combination of features:

- The overall plant design (component reliability, materials, fue 1 cycle, etc.) will be based on a target annual average availability of $92 \%$. An additional 5\% unavailability allowance (i.e., an aggregate of six months per 10 year period) is provided for additionai outages which may be required on occasion for plant modifications, reburshment, etc.

0 The reactor and the support systems will be designed to permit up to two years between refueling and to permit refueling to be accomplished in 18 days, from initial power reduction to return to full power.

- The impact of anticipated routine maintenance items such as pump seals or MSIV refurbishment is to be reduced by application of best available technology in equipment design, and by assigning high priority in plant layout and physical design to facilitate such maintenance activities. 
- Major plant systems such as the power generation systems are simplified to the maximum degree compatible with utility experience.

- The plant will incorporate features to facilitate potential major repairs such as recirculation pipe replacment in BWRs and steam generator replacement in PWRs, thus eliminating extensive forced outages under such circumstances.

- ALWR requircments include availability enhancing features such as deaerators in PWRs, improved control rod drives for BWRs, choice of the best available materials, etc.

- To fully obtain the benefits of the two year periods between refuelings, inadvertent plant trips must be reduced from the preserit level of four or five per year to less than one unplannizd automatic scram per year. To accomplish this, the need for each trip signal will be evaluated, the margin between operating values and trip values will be increased, and the trip circuitry will be changed, as necessary, to make it more tolerant of credible operating and maintenance errors and anticipated equipment failures.

\subsubsection{Plant Life}

The ALWR will have a substantially longer design life than existing plants; the ALWR design life requirement is 60 years. This means the plant is to be designed to operate for 60 years without the need for an extended (multi-year) refurbishment outage. In particular:

- By design, long-term, potentially life-limiting problems will be eliminated. As an example, reactor vessel embrittlement will be limited through the choice of materials and by reducing the high energy neutron flux to the vessel. 
Other major components such as steam generators or recirculation pumps will be designed for the full 60 year life, and also will be designed for replacement or refurbishment as appropriate. The design is to be such that this can be accomplished within the plant down time available while meeting the plant availability requirement of $92 \%$.

- For equipment which is likely to become obsolete and require replacement over the life of the plant, such as instrumentation and control equipment, replacement is to be anticipated and facilitated in the plant design and arrangement.

\subsubsection{Radwaste}

The ALWR will be designed for greatiy reduced production of dry and wet radioactive waste to be shipped off-site. The ALWR is to produce no more than $2500 \mathrm{ft}^{3} /$ year of shipped radioactive waste. To achieve this:

- Waste generation will be reduced, primarily via application of utility experience in the design and operation of plant systems. As examples, BWRs will use throwaway operation of the ir condensate demineralizer resins and PWRs will make greater use of demineralizer as opposed to evaporator processing of liquid wastes.

- Utility experience will be applied in simplifying and improving existing waste processing equipment. Examples are the use of better desigried evaporators, and the separation of waste streams with better monitoring to prevent unnecessary processing of nonradioactive or low activity wastes. 
- The ALWR plant will include use of the latest proven volume reduction technology (compactors, incinerators, etc.) to reduce shipped waste volume to a minimum.

\subsubsection{Personnel Exposure}

The ALWR is to be designed and constructed so that occupational exposure will be less than $100 \mathrm{man}-\mathrm{rem} / \mathrm{yr}$ averaged over the lifetime of the plant, a performance substantially better than most existing plants and comparable to the best LWR plants in the world today. To achieve this goa ?:

0 The materials of the plant and the water chemistry are selected to reduce corrosion and the build-up of radioactive deposits. Low cobalt materials are to be used where practical to reduce that source of personnel exposure.

- A major source of radioactive exposure in current plants is nonroutine maintenance and repairs such as steam generator maintenance and repair, and recirculation pipe replacement and repairs. The ALWR plant will incorporate basic design features to preclude the recurrence of these problems. It will also include features to facilitate such major repairs and reduce exposure if they are found to be needed some time in the life of the plant.

- A major source of radiation exposure is routine preventive maintenance and inspections. The ALWR design will incorporate components which minimize the need for such routine maintenance, such as longer life pump seals, and reduced number of welds.

- The repair and inspection capabilities will also be designed into the plant from the outset in such a way as to minimize the need for personnel exposure. As examples, BWR control rod drives on the reactor vessel bottom head will be designed for 
replacement by remote machines, PWR steam generator installation will be designed for inservice inspection via remotely operated equipment, and access for inspection, maintenance and repair throughout the plant will be greatly improved.

\subsubsection{Operability and Maintainability}

The ALWR must be designed with extremely high attention to operabllity and maintainability, if the avallability and life-cycle cost targets outlined above are to be achieved.

Operability will be addressed in every aspect of the design. The fundamental design philosophies outlined in 1.2 above, particularly simplicity and design inargin, should yield an ALWR design which is outstanding from an operability standpoint. Additionaliy, in-depth attention to human factors principles will be applied in developing arrangement and configuration of the control rooms and other control stations.

Maintainability features include:

- Components and equipment will be standardized thoughout the plant so that a minimum of different types and sizes are used. This will also simplify maintenance procedures and spare parts control and stocking.

- Ventilation and illumination will be designed to ensure that adequate working conditions exist wherever operations, maintenance or inspections must be performed, taking into account the loss of effectiveness caused by protective clothing.

- Adequate platforms, access, lifting capacity, heavy load transfer equipment and pathways, laydown space and necessary services (air, water, electrical power, etc.) will be provided for plant equipment. 
- Adequate facilities will be provided for controlled access to the plant or portions of the plant. The facilities will be based on processing realistically large numbers of personnel prompt 1y.

- The plant arrangement will provide features to facilitate the replacement of al1 major plant components, consistent with the 60 year design life of the plant. Such major plant components include main steam isolation valves, steam generators, reactor coolant pumps, feed-pumps, feedheaters, condenser tube bundles, etc.

\subsection{Cost}

The fundamental objective that the ALWR be an economically competitive plant requires that cost targets and cost control methods be established and implemented. Cost targets include both initial capital cost and life-cycle cost and are needed bases for assigning prioritles and assessing various design alternatives. A life cycle cost target is chosen of $6.5 \% / \mathrm{kwh}$, based on dollars levelized for 30 years of operation starting in 1999 and, then, deescalated to 1985. This target represents substantial improvement over current nuclear plant experience and is also expected to result in a substantial cost advantage over fossi1fired power plants. Targets for the major components of life-cycle cost are $4.5 \phi / \mathrm{kwh}$ for capital cost, $1.2 \phi / \mathrm{kwh}$ for fue 1 cost and $0.8 \% / \mathrm{kwh}$ for operation and maintenance cost. Each of these represents a significant improvement over current plants; the largest improvement is expected in capital costs consistent with the major thrust of the ALWR requirements to reduce the construction schedule, and simplify and standardize the plant design. 


\subsection{Constructability}

The requirements imposed on the ALWR design and construction by the Requirements Document directly address the ALWR fundamental objective of predictable construction cost and schedule. In particular:

- The ALWR plant is to be designed to support a first-plant construction schedule of no more than 54 months from start of structural concrete placement through initial operation. To provide high confidence that the construction schedule can be met, a very high degree of completion of planning and design is required prior to construction. This is a realistic objective, particularly in light of experience gained in overseas LWR construction projects.

- Cinstructability is explicitly considered in the ALWR plant desizn by providing adequate space and arrangement for construction activities and eliminating features in plants which have caused particular construction problems, e.g., complicated curved shapes to be poured in concrete, use of unrealistic construction tolerances, etc.

- Advanced, proven construction techniques are to be utilized to increase productivity and construction efficiency. These include increased use of prefabricated assemblies or modules, automatic welding, high lift concrete pumps, high capacity cranes, computer aided drafting and planning, automated cable tracing, etc.

- An overa 11, integrated plan is required at the outset which addresses construction, system completion, testing and operator/owner acceptance. This plan is to be based on a thorough review of problems experienced in existing LWRs to prevent their recurrence. The construction plan is to be developed jointly by design and construction personnel to obtain 
maximum benefit. It will specify measures, such as to assure utilization of computer-aided techniques in construction sequencing and overal1 project planning and control, to obtain early detection and prompt resolution of problems through quantitative tracking of the work in progress.

Particular attention to quality is required to avold the delays which have adversely impacted some U.S. LWR construction projects. Emphasis will be placed on early identification and resolution of quality problems, effective documentation methods, and direct management involvement in the field. 


\section{ALWR IMPLEMENTATION}

The ALWR Requirements Document is the first step in the development of a new generation of nuclear plants for the 1990 's and beyond. While the exact chronology of events leading to commercial operation of the first ALWR cannot be predicted, an overall sequence is envistoned as depicted in Figure 1. As shown, this sequence leads from generic ALWR requirements (the Requirements Document), through NRC certification of several NSSS designs and the subsequent development of at least one detalled standard plant design and finally to the design, construction and operation of the first ALWR.

\subsection{Generic Plant Requirements}

The first step in ALWR implementation is to produce the ALWR Requirements Document, which defines requirements applicable to any advanced LWR. It wi11 be produced as a series of chapters. Each wi11 be issued for use after utility review and approval, and after NRC approval. NRC approva 1 will be in the form of a Safety Evaluation Report for each chapter, and one for the requirements documents as a whole.

\subsection{NRC Certification}

NRC Certification of several plant designs (each based on a particular NSSS) will proceed in parallel with preparation of the Requirements Document. The purpose of this effort is to establish an NRC certified basis which can be used as a starting point for the detailed design of one or more standard ALWR plants. The Department of Energy is sponsoring the development by BWR and PWR teams of such certified designs, working closely with EPRI to ensure that the designs conform to the Requirements Document. 


\subsection{Standard Plant Destgn}

The next step is expected to be the detalled design of one or more standard plants, of specific NSSS and size, and designed for the standard site-envelope defined in the Requirements Document. The intent would be to develop a plant design in sufficient detail to permit an owner to commit to constructing the plant, and to proceed rapidly with construction once committed.

The standard design(s) would conform to the Requirements Document and the NRC certification. It would be taken to a very high level of completion to ensure confidence in cost and schedule estimates. It is estimated that at the completion of the standard plant design, $70 \%$ of al1 the engineering documents wil1 have been completed, so that the ALWR plant procurement, construction, and site-specific engineering could proceed unimpeded.

A design team would be established to first select the NSSS and then proceed with the detailed design of the entire plant. A major element in this detalled design effort is the specification and selection of plant equipment, including the production of vendor engineering information by the equipment suppliers and incorporation of that information into the design.

The design team would probably include participation by utilities, plant designers, and constructors. The Requirements Document is based on the premise that utilities will play an active role in developing a standard design, and contains many requirements to ensure that a design satisfactory to the utilities is produced. For example:

- Utility review and approval is required of any departure from successful LWR experience. 
- Design criteria and system features must be established early for utility review.

- The designers must participate with the utility in interdisciplinary reviews.

- The overal1 configuration management system must be structured so that the design and construction information smoothly integrates with the utility's future operational and maintenance needs.

The exact genesis and structure of the teams which will develop a standard plant design cannot be foreseen at this time. Ii is clear, however, that with the very high level of design completion and the extensive utility interaction required, such a standard design wi11 demand a major commitment of time, talent and money by the utilities, architect/engineers and constuctors alike. It may well be that a group of utilities with the necessary interest in and experience with LWRs will band together to fund and direct the effort.

\subsection{Specific Plant (First ALWR) Design and Construction}

This step includes the efforts needed to proceed from a standard design to the final detailed design, construction, and operation of the plant.

It is assumed that some effort would be undertaken in parallel with the standard design to permit imely completion of the plant once a commitment to construct is made. In particular:

- A specific site would be selected and the various evaluations required to ensure that it is suitable would be performed. 
- Plant licensing would be initiated in parallel with the standard design. The rechnical basis for licensing would include (1) the certifled design, (2) additional plant information developed in accordance with the NRC approved Requirements Document during the standard design effort, and (3) site-specific engineering performed before construction commitment to the extent necessary to establish that regulatory requirements are met. A "one-step" licensing procedure is assumed to be in place, which would result in NRC approval of the plant shortly after an owner committed to construct it.

- Additional site-specific engineering would be performed to permit site preparation work to start once a license is received, and for pre-planning of facilities construction.

Once an owner comits to construction, the following major activities would proceed:

- Site-spectfic engineering would proceed for the actual plant. The Requirements Document requires that the completion level of the design be sufficient to support all project planning and mobilization activities (construction, procurement, QA, startup, etc.) prior to the placement of first structural concrete. Further, it requires that the design completion be sufficient at any point in time to support construction for two years without issuing additional documents. Finaliy, the document requires that total design be complete two years after start of construction (first structural concrete). It is estimated that these requirements will result in 90\% of al1 the engineering documents (standard plus plant specific) necessary to complete the plant having been issued prior to start of construction. 
- Purchase of actual equipment would begin immediately, based on the equipment selection and vendor engineering efforts in the standard plant design. It would proceed on a schedule whtch ensures equipment is delivered to the site when required.

- Site preparation would also begin immediately, as the necessary precursor to plant construction.

- The construction and startup phases are estimated to require 54 months for the first ALWR (from first structural concrete to commercial operation). The high degree of design completion includes detalled construction and startup planning to support this schedule. 


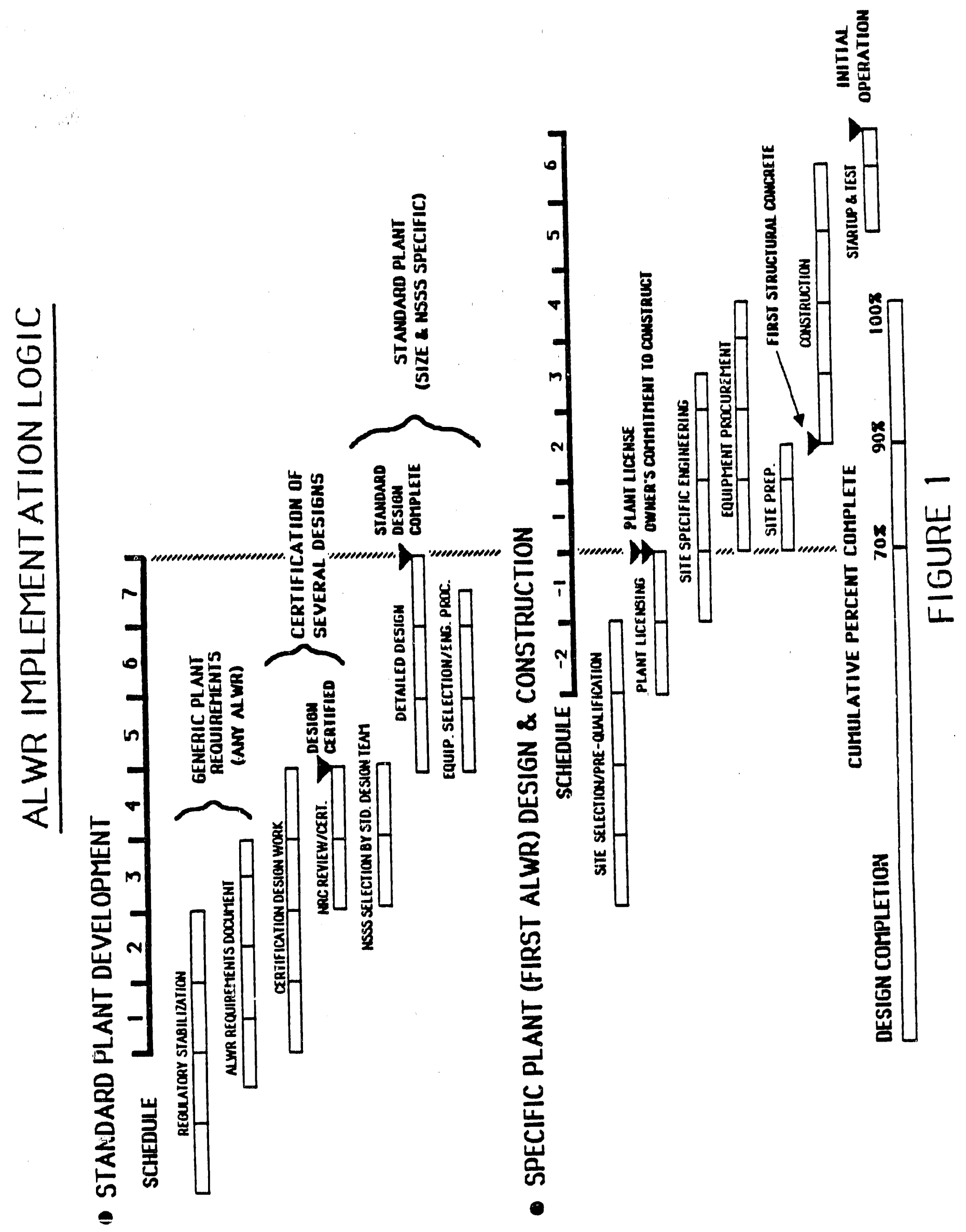


In summary, the development of an advanced light water reactor is an ambitious undertaking, yet is one which is firmly rooted in technical reality. Notwitistanding the marketing and political factors, which at this point remain unpredictable, the EPRI Requirements Document will define a nuclear plant which will be a safe, practical, and economically viable means of serving the nation's electric power generation needs in the decades ahead. 


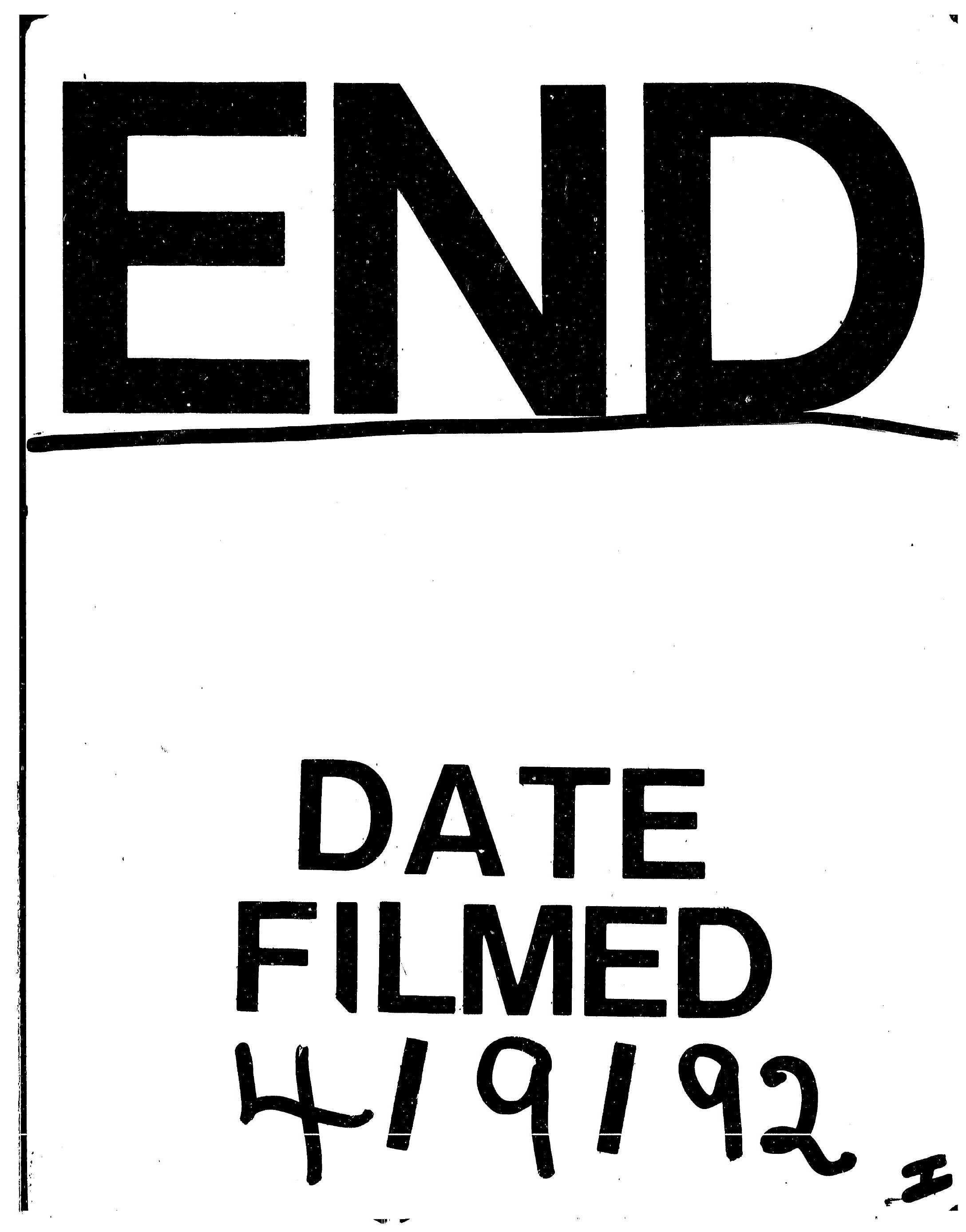


